\title{
Diaphragmatic Hernia with Stomach Rupture after Blunt Chest Trauma at a Short Interval: A Case Report
}

\author{
Seung Hyong Lee, M.D. ', Sun-Geun Lee, M.D. ${ }^{2}$, Dae Hyun Kim, M.D. ${ }^{2}$, Sang-Ho Cho, M.D. ${ }^{2}$, Jae Won Song, M.D. ${ }^{2}$, \\ Won Kyoun Park, M.D. ${ }^{2}$
}

'Department of Thoracic and Cardiovascular Surgery, Kyung Hee University Hospital, College of Medicine, Kyung Hee University; ${ }^{2}$ Department of Thoracic and Cardiovascular Surgery, Kyung Hee University Hospital at Gangdong, College of Medicine, Kyung Hee University, Seoul, Korea

\section{ARTICLE INFO}

Received July 15, 2021

Revised October 1, 2021

Accepted November 8, 2021

Corresponding author

Won Kyoun Park

Tel $82-2-440-6158$

Fax 82-2-440-8004

E-mail medkyoun@khnmc.or.kr

ORCID

https://orcid.org/0000-0002-1693-0582

\begin{abstract}
Diaphragmatic hernias have been reported in $0.8 \%-1.6 \%$ of patients who experience blunt chest trauma. The hernia is assumed to form as a result of direct diaphragmatic violation or significant intraabdominal or intrathoracic pressure caused by the trauma. Some reports have described cases of delayed diaphragmatic hernia and subsequent stomach perforation that occurred a few days to several years after an accident. We report an extremely rare case of diaphragmatic herniation in which the process from initial blunt trauma to visceral organ perforation took only 2 days, without any evidence of herniation on the initial X-ray or computed tomography. Delayed diaphragmatic herniation and subsequent visceral organ perforation should not be missed during the period immediately after blunt chest trauma.
\end{abstract}

Keywords: Traumatic diaphragmatic hernia, Rupture, Stomach, Thoracotomy, Laparoscopy, Case report

\section{Case report}

This study was exempted from Institutional Review Board (IRB) review by the IRB of Samsung Medical Center (IRB approval no., 2021-10-007). And informed consent was waived.

A previously healthy 58-year-old man presented to the emergency department with left chest wall pain and dyspnea. He had a 35-pack-year smoking history and had fallen from his bicycle on the day of the visit. Emergency chest computed tomography (CT) demonstrated multiple rib fractures of the left first to eighth ribs and left scanty hemopneumothorax with subcutaneous emphysema, without diaphragmatic herniation. His initial vital signs were stable, and his abdomen was not distended. His biochemical laboratory findings were also normal. On hospital day 2, the patient complained of severe dyspnea and chest pain. Chest radiography revealed a large pneumothorax on the left side. A chest tube was inserted, and a newly developed diffuse haziness was observed on chest radiography. Emergency chest CT demonstrated diaphragmatic rupture with herniation of the stomach and hemopneumothorax (Fig. 1). Emergency surgery was performed. The pleural cavity was exposed via the fourth intercostal space by standard posterolateral thoracomty. A contaminated thoracic cavity with stomach contents was observed, without pleural adhesions. There was an approximately $6-\mathrm{cm}$ defect in the diaphragm and a $2-\mathrm{cm}$ rupture in the stomach (Fig. 2). Abundant irrigation and direct repair of the defected diaphragm were performed in the thoracic field, followed by resection and closure of the region around the perforation of the stomach using 2 Echelon 45-mm linear staplers (Ethicon, Somerville, NJ, USA) with a blue cartridge, laparoscopically by the general surgery team. Inspection of the abdominal cavity was also done during laparoscopic surgery, but there was no evidence of peritonitis. The operation was completed after the placement of drains in the thoracic and abdominal cavities. The operation time was 220 minutes and the estimated blood loss was $200 \mathrm{~mL}$. Ventilator management and antibiotics (empirically, vancomycin and meropenem) were provided. Extubation was performed on postoperative day 4. Vancomycin and meropenem were 

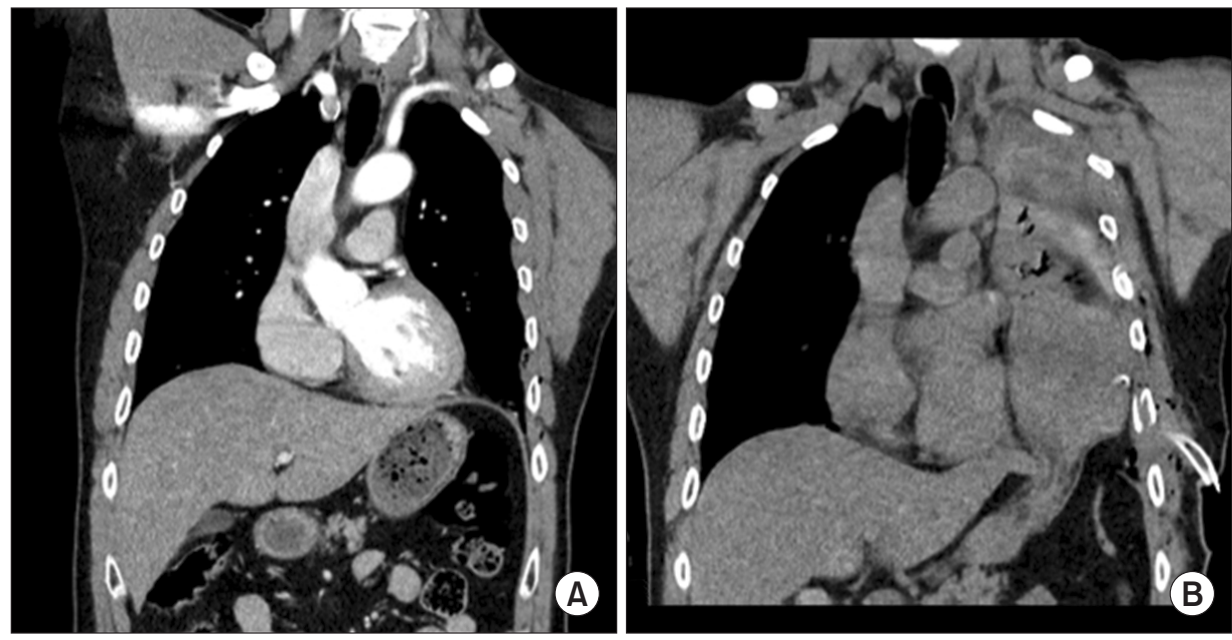

Fig. 1. Initial chest computed tomography (CT) image (A). Diaphragmaic herniation is shown on a chest $\mathrm{CT}$ on hospital day 2 (B).


Fig. 2. Contamination of the thoracic cavity with bowel contents was shown (A) in the initial inspection of the pleural cavity. A 6-cm diaphragmatic rupture $(B)$ and a 2-cm stomach rupture $(C)$ were also identified.

administered for 1 week and changed to ampicillin and sulbactam for 2 weeks. Infection markers such as C-reactive protein and white blood cell count gradually reduced from 24.8 to $1.5 \mathrm{mg} / \mathrm{dL}$, and from $11,980 / \mathrm{mm}^{3}$ to $7,370 / \mathrm{mm}^{3}$, respectively, from the operative day to the discharge day. The patient was discharged on postoperative day 27 without experiencing any adverse events during the hospital stay. The patient has been doing well, without complications, for 2 years from discharge.

\section{Discussion}

Traumatic diaphragmatic hernia occurs in $0.8 \%-1.6 \%$ of patients who suffer blunt trauma. Several reports have shown that initial chest radiography is normal, even if diaphragmatic hernia is present $[1,2]$. The progression of traumatic diaphragmatic hernia is classically divided into 3 phases: (1) the immediate phase following the accident, (2) the interval phase, and (3) the obstruction or strangulation phase [3]. To explain how occult diaphragmatic defects proceed from phase 2 to phase 3 , it has been hypothesized that respiration consistently pulls the defected diaphragm radially, gradually extending the size of the defect. Finally, herniation of the viscera becomes possible through the initial occult defect [4]. The negative pressure of the chest and the positive pressure of the abdomen induce visceral organ herniation, especially on the left side $[5,6]$. This explains why initially asymptomatic chest trauma patients presenting with chest or abdominal symptoms have been demonstrated to develop delayed diaphragmatic hernia, strangulation of visceral organs, and even fecopneumothorax within a few days or even years. Although this rare and easily overlooked trauma can lead to poor patient outcomes, there is no consensus regarding the indication of preventive diagnostic procedures, such as laparoscopic exploration for blunt chest trauma patients, and occult diaphragmatic injuries are often neglected until they become symptomatic. Moreover, the interval between each phase remains unknown, the absolute interval. Although we reviewed reports on delayed herniation presenting after blunt chest trauma, the literature only shows that the interval from initial blunt trauma to organ perforation ranges from 11 days to 8 years $[2,7]$.

We believe that the reason for the shortened progression in this case was that the patient had not been kept on an only-by-mouth status during initial management due to 
the absence of evidence of herniation or bowel perforation on the initial work-up. This probably led to increased bowel content, and subsequently increased stomach pressure, which culminated in the rupture and enlargement of the diaphragmatic defect and stomach defect that had already existed after the accident but had not been large enough to be detected on initial chest CT. In conclusion, delayed diaphragmatic herniation and subsequent visceral organ perforation should not be missed during the acute phase of the clinical course.

\section{Conflict of interest}

No potential conflict of interest relevant to this article was reported.

\section{ORCID}

Seung Hyong Lee: https://orcid.org/0000-0002-9839-6431

Sun-Geun Lee: https://orcid.org/0000-0002-7509-0229

Dae Hyun Kim: https://orcid.org/0000-0002-8434-7380

Sang-Ho Cho: https://orcid.org/0000-0001-5590-1904

Jae Won Song: https://orcid.org/0000-0002-3530-0623

Won Kyoun Park: https://orcid.org/0000-0002-1693-0582

\section{References}

1. Onakpoya U, Ogunrombi A, Adenekan A, Akerele W. Strangulated tension viscerothorax with gangrene of the stomach in missed traumatic diaphragmatic rupture. ISRN Surg 2011;2011:458390.

2. Goh BK, Wong AS, Tay KH, Hoe MN. Delayed presentation of a patient with a ruptured diaphragm complicated by gastric incarceration and perforation after apparently minor blunt trauma. CJEM 2004;6: 277-80.

3. Carter BN, Giuseffi J, Felson B. Traumatic diaphragmatic hernia. Am J Roentgenol Radium Ther 1951;65:56-72.

4. D'Souza N, Bruce JL, Clarke DL, Laing GL. Laparoscopy for occult left-sided diaphragm injury following penetrating thoracoabdominal trauma is both diagnostic and therapeutic. Surg Laparosc Endosc Percutan Tech 2016;26:e5-8.

5. Shah R, Sabanathan S, Mearns AJ, Choudhury AK. Traumatic rupture of diaphragm. Ann Thorac Surg 1995;60:1444-9.

6. Bunya N, Sawamoto K, Uemura S, et al. How to manage tension gastrothorax: a case report of tension gastrothorax with multiple trauma due to traumatic diaphragmatic rupture. Int J Emerg Med 2017;10:4.

7. Kafih M, Boufettal R. A late post-traumatic diaphragmatic hernia revealed by a tension fecopneumothorax (a case report). Rev Pneumol Clin 2009;65:23-6. 